\title{
Modulations in Anti-Oxidant Activities of Selected Gastro-Intestinal Tissues in Alloxan-Induced, Silymarin Treated Diabetic Wistar Rats
}

\author{
Johnson Uyovwiesevwa Ataihire*, Eze Kingsley Nwangwa, John Chukwuka Igweh \\ Department of Human Physiology, Faculty of Basic Medical Sciences, College of Health Sciences, Delta State University, \\ Abraka, Nigeria \\ Email: *osgiedeprof@yahoo.com, *ataihire@yahoo.com
}

How to cite this paper: Ataihire, J.U., Nwangwa, E.K. and Igweh, J.C. (2019) Modulations in Anti-Oxidant Activities of Selected Gastro-Intestinal Tissues in Alloxan-Induced, Silymarin Treated Diabetic Wistar Rats. Open Journal of Gastroenterology, 9, 73-90.

https://doi.org/10.4236/ojgas.2019.95010

Received: April 15, 2019

Accepted: May 28, 2019

Published: May 31, 2019

Copyright $\odot 2019$ by author(s) and Scientific Research Publishing Inc. This work is licensed under the Creative Commons Attribution International License (CC BY 4.0).

http://creativecommons.org/licenses/by/4.0/

\begin{abstract}
Diabetes mellitus (DM) is reportedly the commonest metabolic disorder with multi organ involvement. By inducing DM (with Alloxan) in Wistar rats, current study investigated the changes in antioxidant activities of selected gastrointestinal (GI) tissues [stomach, duodenum, pancreas and liver], upon treatment with Silymarin and/or Vitamin C. One hundred and twenty five (125) adult male wistar rats of between 130 to 180 grams were procured for the study. Five units of one control and four experimental units were designated with twenty five (25) rats per group $(\mathrm{n}=25)$; Unit 1 : Control rats, Unit 2 were DM induced, Silymarin untreated rats, and Units 3, 4 and 5 were DM induced, vitamin C, Silymarin and Vitamin C + Silymarin treated respectively. Following four (4) weeks of administration of test substance(s), rats were euthanized and blood samples obtained for biochemical and antioxidant assay on aforementioned GI tissues. One way analysis of variance (ANOVA) and Students t-test at $p<0.05$ were set to be statistically significant on analysis of obtained data. First, study found DM to have caused a statistically significant decrease in body weight prior to sacrifice. Catalase (CAT), superoxide dismutase (SOD) and malonaldehyde (MDA) levels were also seen to significant increase $(p<0.05)$ at comparison of extract treated unit to control. Study also observed a significant change in pancreatic, liver, and duodenal anti-oxidant marker levels with Vitamin C, Silymarin and Vitamin C + Silymarin co-administrations to diabetic rats. It can therefore be said, that DM caused a destructive alteration pancreatic histo-architecture with improved functional capabilities in wistar rats at administration of Silymarin and vitamin C. Thus, Silymarin posed antioxidant potentials, with ameliorated pancreatic dysfunctions.
\end{abstract}




\section{Keywords}

Silymarin, Antioxidant, Diabetes Mellitus

\section{Introduction}

Overtime, a good number of antioxidants have been exploited in the management of Diabetes disorders. These agents reportedly play vital roles in the scavenging free radicals. By this act, they provide protection against infections and degenerative diseases [1] [2]. Over the years, Silymarin and vitamin C have received huge attentions on this role through their antioxidant and hepatoprotective potentials [3].

Silybum marianum (aka Milk thistle), is an ancient medicinal plant of the member Carduus marianum family. It has explored for centuries in the management of different diseases such as liver and gallbladder disorders. It is known to protect the liver against snake bites and insect stings, mushroom poisoning and alcohol abuse; and can be found in Kashmir, North America, Canada and Mexico with large leaves and reddish-purple thorny flowers, with medicinal part as either the seeds or fruits [3] [4] [5].

Studies have shown silymarin as consisting primarily of three varieties of flavanolignans; silychristin (silichristin), silybin (silibinin) and sylichristin B, and silidianin. It also contains other flavanolignans as dehydrosilybin, 3-desoxysilichristin, deoxysilydianin (silymonin), siliandrin, silybinome, silyhermin, and neosilyhermin [6] [7]. Other constituents of silymarin thistle include: taxifolin, apigenin, silybonol, linoleic and oleic acids, palmitic, myristic, and stearic acids, betaine hydrochloride, histamine and triamine.

Several reports have predicted different mechanisms of action of silymarin to include its ability to increase regenerative ability damaged hepatocytesvia enhancements of DNA and RNA synthesis [8]. Due to its steroid nature, this mechanism is theoretically achieved via Alteration of hepatocytes' external membrane, preventing subsequent entrance of the xenobiotics (poisoning with Amanita mushroom is a noteworthy example of such mechanism), and scavenging free radicals to increase cellular glutathione content. This act, thus leads to the inhibition of lipid peroxidation in affected tissues. Again, another possible mechanism of action of silymarin is via modification of cellular transporters and receptors. Such transporters as the $\mathrm{ABC}$ transporters (P-gp), organic anion uptake transporter peptides (OATP), bile salt export pump, and TNF- $\alpha$-dependent transporters [9] [10].

Antioxidants studies in experimental models have strongly suggested their beneficial effects in reducing complications in diabetes [8]. However, clinical evidences for the use of antioxidants are inconclusive. Though clinical trials with antioxidants in diabetes are limited, few of these trials focus on the use of vitamins E, C and lately, $\alpha$-lipoic acid. Recently however, interests have developed 
on the product Silymarin, a unique flavonoid complex-containing silybin, silydianin, and silychrisin-that is derived from the milk thistle plant discovered by a German scientist in 1981 [11].

The uniqueness in Silymarin phyto-chemitry has been the subject of decades of research into their beneficial properties. Over the years, itshepato-protective and decongestant role has earned it its fame [12] [13] [14]. Revelation from previous studies has therefore prompted interests for further studies on this product. Hence the study intends to research if Silymarin can be used as a better antioxidant than the commonly researched vitamins to relieve the damaging oxidative stress effects generated in diabetes.

\section{Aim of Study}

This study investigated the anti-oxidant potency of Silymarin, and its usefulness in addition to conventional anti-diabetic drugs so as to properly harness its phytochemicalsin modern management of diabetic mellitus. Specifically, Study:

1) Determine the effects of diabetes mellitus and some antioxidants on body weights of Wistar rats.

2) Examined the changes in the levels of anti-oxidant activities for selected Gastro-Intestinal tissues insilymarin and vitamin C. co-administration to alloxan induced Diabetic wistar rats.

3) Determined the alterations in oxidative stress markers and attenuating effect of antioxidants in alloxan-induced diabetes mellitus in Wistar rats.

\section{Materials and Methods}

\subsection{Study Location}

Study was conducted in the Department of Human Physiology, College of Health Sciences, Delta State University, Abraka, Delta State, Nigeria. Delta state is a 16,842 square kilometer (6503 sq meters) area of land located approximately between longitude $5^{\circ} 00$ and $6^{\circ} .45^{\prime}$ East and latitude $5^{\circ} 00$ and $6^{\circ} .30^{\prime}$ North of the equator. It is a densely populated area of an estimated population of 4112.445 $(2,069,309$ males and 2,043,136 females) [13].

\subsection{Study Design}

Two hundred and seventy five (275) adult Wistar rats weighing between 130 to 180 grams and aged between six to eight weeks were used for the study. The animals were then acclimatized for two weeks and shared into Five groups of one control (group I) and four experimental units (groups 2-5), each group had twenty five (25) rats per group $(\mathrm{n}=25)$ as follows:

\begin{tabular}{cccc}
\hline Groups & $\begin{array}{c}\text { Number } \\
\text { of rats }\end{array}$ & Remark & $\begin{array}{c}\text { Duration of } \\
\text { Administration }\end{array}$ \\
\hline $\begin{array}{c}\text { Group I } \\
\text { (Control) }\end{array}$ & 25 & $\begin{array}{c}\text { Fed with standard } \\
\text { rat feeds and water ad libitum }\end{array}$ & 4 weeks \\
\hline
\end{tabular}




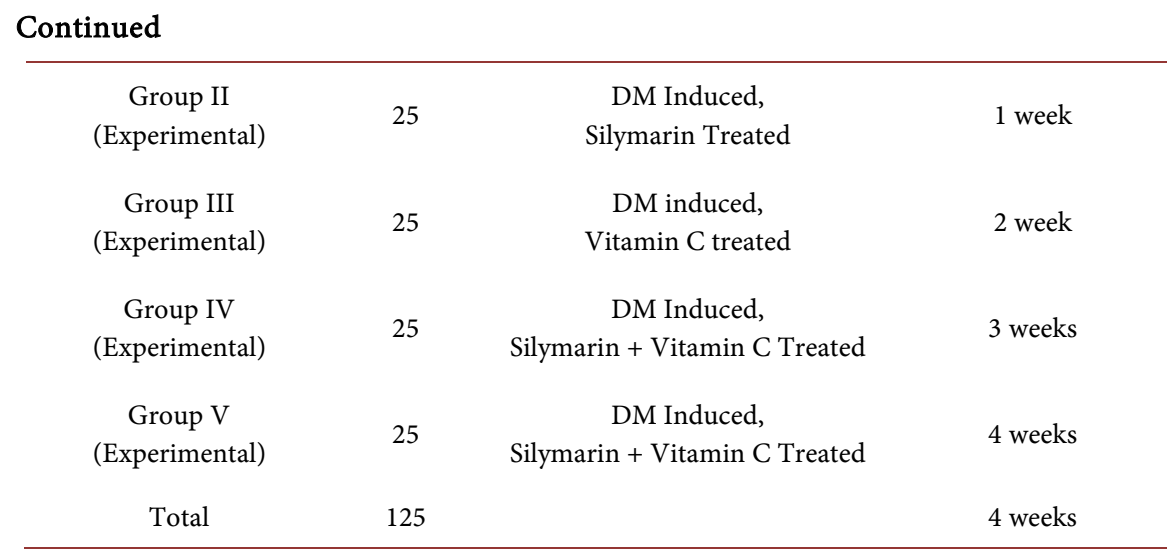

\section{Procedure}

\subsection{Resources and Sources}

Silymarin was procured from Sigma-Aldrich Chemicals Company (St. Louis, Mo, USA). Vitamin C is a product of Emzor Pharmaceuticals, Lagos, Nigeria. Assay kits were purchased from Randox Laboratories Limited, United Kingdom and Sigma-Aldrich Chemicals Company (St. Louis, Mo, USA). Distilled water was obtained from Physiology Laboratory, Delta State University Abraka Nigeria. Animals for the study were purchased from the animal unit of the College of Medicine, Ambrose Alli University Ekpoma in Edo State of Nigeria.

\subsection{Weighing the Rats}

With minimal restraint each rats were carefully placed in electronic animal weighing scale and weighed in grams. This was done each week before and after treatment throughout the period of the experiment.

\subsection{Drug Administration}

Alloxan: Alloxan monohydrate was administered at $140 \mathrm{mg} / \mathrm{kg}$ b.wt by ip injection for induction of diabetes mellitus [14].

Silymarin: Silymarin was administered at $30 \mathrm{mg} / \mathrm{kg}$ bodyweight once daily using oral intubation, (gavage) with ad libitum provision of food and water [15].

Vitamin C: was administered at $100 \mathrm{mg} / \mathrm{kg}$ body weight once daily also throughout the experimental period using oral intubation (gavage) with ad libitum provision of food and water [16] [17].

Thiopentone Sodium: Thiopentone sodium was administered using $30 \mathrm{mg} / \mathrm{kg}$, intraperitoneally [18].

\subsection{Induction of Diabetes Mellitus}

Diabetes mellitus was induced in the group of rats by a single intraperitoneal injection of $140 \mathrm{mg} / \mathrm{kg}$ body weight alloxan monohydrate freshly dissolved in citrate buffer ( $\mathrm{pH}$ 4.5) after overnight fast Wistar rats [19]. Body weight and basal blood glucose levels were measured just prior to Alloxan injection using ani- 
mal-balance and an automated glucose analyzer (glucometer) respectively. A drop of blood sample was collected by a prick on the tail vein.

\subsection{Confirmation of Hyperglycemia}

The level of serum glucose considered to be normal in Wistar rat ranges from 50 to $135 \mathrm{mg} / 100 \mathrm{ml}$ (Harkness and Wagner, 1993). Diabetes mellitus was confirmed 48 hours after Alloxan injection in the rats by the presence of blood glucose levels above $200 \mathrm{mg} / \mathrm{dl}$. Monitoring of the glucose was continued weekly to ensure sustained diabetes throughout the experiment. A rest period of 12 days for the rats was allowed before commencement of the experiment during which they have free access to food and water [20].

\subsection{Collection of Blood Samples for Analysis}

After preparation of the rats, they were anaesthetized as done by Shivkumar using $30 \mathrm{mg} / \mathrm{kg}$, i.p thiopentone sodium [21]. The abdomen was opened and blood samples were collected directly from the heart by cardiac puncture. Various tissues were collected, weighed, homogenized in phosphate buffer and centrifuged at $4000 \mathrm{rpm}$ for $10 \mathrm{mins}$ and the supernatant was stored in refrigerator at $4^{\circ} \mathrm{C}$ before use. Homogenization of tissues was done for tissue antioxidants.

\subsection{Analysis of Oxidative Markers}

Oxidative stress Markers analyzed includes; Superoxide Dismutase (SOD), Catalase (CAT) and Malondialdehyde (MDA) activities

\section{Determination of Superoxide Dismutase (SOD) Activity}

SOD activity was determined as described by Misra and Fridovich (1972) and adopted by Isamah, et al., 1994 [19] [21]. The principle is based on the fact that SOD inhibits the auto-oxidation of Epinephrine by superoxide radical generation.

\section{Procedure}

The reaction mixture containing $0.2 \mathrm{ml}$ of the tissue suspension and $2.5 \mathrm{ml}$ of $0.05 \mathrm{mM}$ of carbonate buffer at $\mathrm{pH}$ of 10.2 was mixed by inversion. A reference cuvette containing $2.5 \mathrm{ml}$ of the buffer, $0.2 \mathrm{ml}$ of water and $0.3 \mathrm{ml}$ of the substrate (epinephrine) was then added. The increase in absorbance was monitored at $480 \mathrm{~nm}$ every 30 seconds for 150 seconds. Percentage inhibition of SOD activity was then estimated as the volume of supernatant corresponding to $50 \%$ inhibition of the reaction. It was expressed as. $\mu \mathrm{g} / \mathrm{mg}$ protein

\section{Determination of Catalase (CAT) Activity}

Catalase activity was determined as described by the method of Aebi (1983) [22]. The principle is based on the understanding that Catalase converts $\mathrm{H}_{2} \mathrm{O}_{2}$ to water and molecular oxygen according to the equation 


$$
2 \mathrm{H}_{2} \mathrm{O}_{2} \rightarrow 2 \mathrm{H}_{2} \mathrm{O}+\mathrm{O}_{2}
$$

\section{Procedure}

$0.1 \mathrm{ml}$ of the homogenates (supernatant) was pipette into a cuvette containing $1.9 \mathrm{ml}$ of $500 \mathrm{mM}$ phosphate buffer, $\mathrm{pH}$ 7.0. The reaction was started by the addition of $1.0 \mathrm{ml}$ of freshly prepared $30 \% \mathrm{v} / \mathrm{v}$ hydrogen peroxide $\left(\mathrm{H}_{2} \mathrm{O}_{2}\right)$. Catalase activity was measured spectrophotometrically from decrease in absorbance at $240 \mathrm{~nm}$. Decrease of absorbance was recorded in every 15 seconds up to $3 \mathrm{~min}$. Amount of catalase enzyme was expressed as $\mu \mathrm{g} / \mathrm{mg}$ protein.

\section{Determination of Malondialdehyde (MDA) Activity}

Malondialdehyde (MDA) activity was determined as described by Buege and Aust (1978) and modified by Popham and Novacky (1991) [18] [19] [20]. The principle is adopted because MDA causes Changes in lipid peroxidation, indicative of oxidative stress. This principle then adopts the measurement of the absorbance at $535 \mathrm{~nm}$ spectrophotometrically of the color that MDA forms with Thiobarbituric acid, (TBA) in the acidic media. The amount of MDA formed in each sample was then quantified by its reaction with thiobarbituric acid reactive substance (TBARS).

\section{Procedure}

Lipid peroxidation in the tissue was estimated spectrophotometrically by thiobarbituric acid reactive substance (TBARS\}, according to the method of Buege and Aust (1978) as modified by Popham and Novacky (1991) [23]. $0.1 \mathrm{ml}$ of the stomach tissue homogenate (Tris- $\mathrm{HCl}$ buffer, $\mathrm{Ph} 7.5$ ) was treated with $2 \mathrm{ml}$ of (1:1:1 ratio) TBA-TCA-HCL reagent (thiobarbituric acid $0.37 \%, 0.25 \mathrm{~N}$ HCL and $15 \%$ TCA). The mixture was boiled at $95^{\circ} \mathrm{C}$ for $30 \mathrm{~min}$ and cooled on ice for 5 min. After centrifugation at $10000 \times \mathrm{g}$ for $10 \mathrm{~min}$, absorbance of the supernatant was determined at $532 \mathrm{~nm}$ and corrected for non-specific turbidity by subtracting the absorbance at $600 \mathrm{~nm}$. The concentration of MDA was calculated from its extinction coefficient $\left(155 \mathrm{mM}^{-1} \mathrm{~cm}^{-1}\right)$ and measured in nmols/ml, Nazi Ercan and Mustafa Kockaya (2017) [24].

\section{Ethical Considerations}

Ethical approval was sought and obtained from the Bio-Research and Ethics Committee of the College of Health Sciences Delta State University, Abraka, and Delta State.

\section{Analytical Approach}

Results were expressed as mean \pm SEM. The evaluation of data for significance was done using one-way Analysis of Variance (ANOVA). The statistical data were analyzed using the statistical software SPSS-20. A $p<0.05$ was considered statistically significant. 


\section{Results}

\subsection{Effects of Alloxan-Induced DM on Catalase Levels}

Three markers of oxidative stress; Catalase (CAT) activity, Superoxide Dismutase activity (SOD) and Malonaldehyde (MDA) levels were measured in various tissues and their responses to diabetes and consequent treatment with Vitamin $\mathrm{C}$ and Silymarin were compared as shown in Figures 2-5.

\subsection{Effects of Alloxan-Induced DM on Superoxide Dismutase (SOD) Levels}

Superoxide Dismutase(SOD) activity in the stomach, duodenum, pancreas and liver, similarly showed an increasing enzyme activity when diabetic tissues were compared with treated tissues using vitamin C, Silymarin and a combination of both in all the organs as demonstrated in Figures 6-9. In these tissues it was also clear that diabetes significantly reduced catalase activities when compared with control rats. These findings were found to be similar to catalase activities in similar organs investigated.

\subsection{Effects of Alloxan-Induced DM on Malonaldehyde (MDA) Levels}

The levels of lipid peroxidation using Malondialdehyde (MDA) in the Stomach, Duodenum, Pancreas and Liver, were also investigated in diabetic and diabetic treated groups. An interesting result different from that seen in CAT and SOD was observed. This is shown in Figure 10 \& Figure 11. MDA was noted to be stable during the first two weeks, but these levels increase with continuous oxidative stress. Also their activity was more pronounced in the stomach, duodenal and pancreatic tissues compared to the liver.

\section{Discussion}

This study was conducted to evaluate the modulatory effects of silymarin and vitamin $\mathrm{C}$ on Diabetes, and in alteration of anti-oxidant activity levels in selected tissues of the gastrointestinal tract, using wistar rats as experimental model.

In this study, induction of DM in rats resulted in a statistically significant decrease $(p<0.05)$ in the blood glucose level of rats fed with a single intraperitoneal injection of $140 \mathrm{mg} / \mathrm{kg}$ body weight of alloxan monohydrate, compared to those of the control group of rats (Figure 1).

Alloxan is known to cause DM by rapid depletion of the pancreatic beta-cells, leading to reduction in serum insulin level [22]. Also, the treatment of these diabetic rats with vitamin $\mathrm{C}$, silymarin, and a combination of vitamin $\mathrm{C}$ and silymarin all showed a statistically significant reduction in glucose levels when compared to diabetic rats (Figure 1). Similar studies done earlier by Obembe et al., 2008 [25] using Rutin (also an antioxidant) and vitamin C and their combined treatments for 5 -weeks on diabetic rats caused a decrease in glucose levels, with an unprecedented increase in insulin concentrations when compared to 
diabetic control group of rats [24] [25]. However, in that study, the effects were more pronounced in the group of rats treated with combined vitamins and $\mathrm{Ru}$ tin. Hamden et al. therefore recommended the combined treatments with antioxidant vitamins for DM.

Similarly in this study, the combined effects of using Silymarin and vitamin C as antioxidants can be clearly seen from Figure 1 to be more readily significant than using either vitamin $\mathrm{C}$ or silymarin alone. Results from this study showed that treatment of diabetic rats with silymarin and vitamin-C significantly ameliorated hyperglycaemia, lipid peroxidation, and increased the activities of serum and tissue antioxidant enzymes. Therefore, adjunct treatment of diabetics with vit-C and/or silymarin may be beneficial.

Okon et al., (2003) had earlier reported that antioxidants partake in the general mechanism of glucose transport inhibition and lactate transport stimulation in neuronal and non-neuronal cells. Ascorbic acidis also transported into cells by facilitative glucose transportvia a member of the GLUT family [6] and sodium-dependent, electrogenic process [27]. Results from this study showed that blood glucose level was reduced in diabetic group treated with Silymarin and Vitamin C compared to the untreated rats. This finding is in agreement with a previous study that Vitamin C caused a reduction in blood glucose level in alloxan-induced DM [26]. Thus, inhibition of glucose transport could be a possible mechanism of reduction of blood glucose by vitamin $\mathrm{C}$ in diabetic condition. However, the hyperglycemic state observed in rats became less severe with increasing number of days as depicted by the blood glucose level at the $3^{\text {rd }}$ and $4^{\text {th }}$ weeks following induction of diabetes compared with the first week of the therapy.

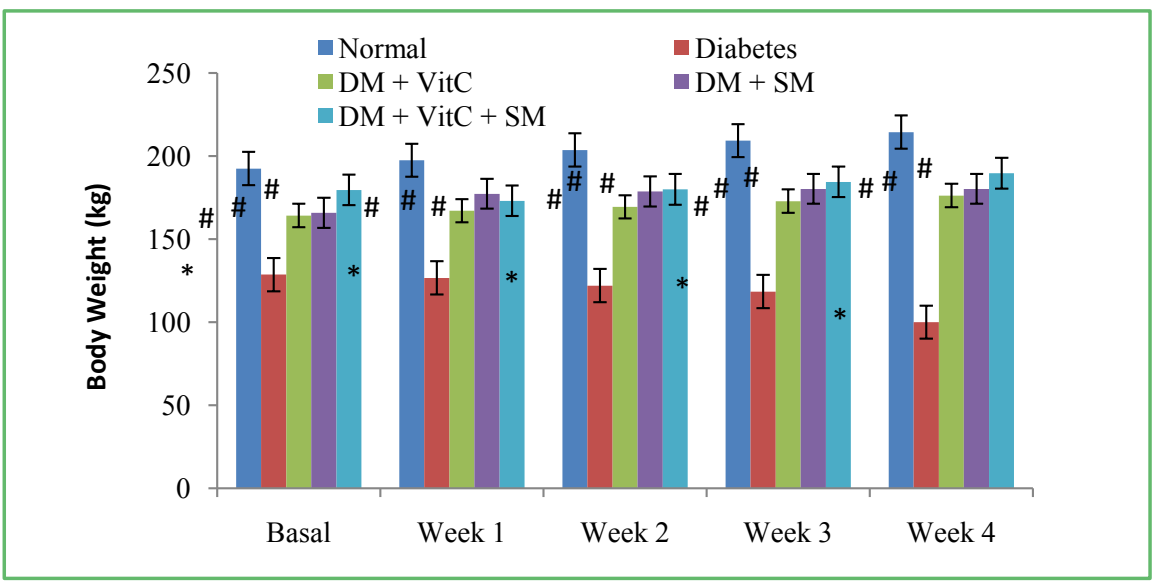

Figure 1. Effects of Alloxan-induced Diabetic on Body Weights of Wistar Rats. The figure shows a significant decrease $(p<0.05)$ in body weight of the rats between second and fourth week following DM induction when compared to the normal rats. However, Vit. C, Silymarin, and vit $\mathrm{C}+$ Silymarin treated diabetic rats showed a significant increase in body weights from second to fourth week of treatment when compared with the diabetic rats. ${ }^{*}=$ Significant reduction of weight at $\mathrm{p}<0.05$ when compared with normal \# = significant increase in body weights $p<0.05$ when compared with diabetes group. 
Also, administration of antioxidants vitamin C, silymarin or a combination of both showed a significant inhibition of alloxan-induced diabetes mellitus and exerts a potent anti-hyperglycemic effect as demonstrated by the significant decrease $(P<0.05)$ in blood glucose with the $100 \mathrm{mg} / \mathrm{kg}$ of vitamin $C$ and $30 \mathrm{mg} / \mathrm{kg}$ bodyweight daily of silymarin used in this study. The insufficient release of insulin caused hyperglycemia which resulted in oxidative damage by generation of reactive oxygen species (ROS) [28] and the development of diabetic complications [29]. Therefore as part of the metabolic process free radicals and reactive oxygen species (ROS) which are destructive to the body are produce by cells [30] from reactivation of fatty acids resulting from the tissue damage.

Antioxidant refers to a compound that can inhibit the oxidation of lipids by deterring the initiation of oxidative chain reactions and which can thus prevent or repair damage done to the cells by oxygen. These compounds act by one or more of the following mechanisms: reducing activity, free radical-scavenging, potential complexing of pro-oxidant metals and quenching of singlet oxygen. The formation of ROS is prevented by an antioxidant system that included non-enzymatic antioxidants (vitamin $\mathrm{C}$, vitamin $\mathrm{D}$ and glutathione), enzymes regenerating the reduced forms of antioxidants, and ROS-scavenging enzymes such as SOD, CAT, GPx and GST [31].

Epidemiological, studies have shown that manyphytonutrients of fruits and vegetables might protect the human body against damage by ROS. The consumption of natural antioxidant phytochemicals was reported to have potential health benefits [32]. Flavonoids are known to have powerful antioxidant activity that could play a protective role inoxidative stress-mediated diseases, and recent attention has been focused on the potential uses of flavonoids-based drugs for the prevention and treatment of these pathologies [33]. Vitamin C and silymarin a flavonoid have strong antioxidant properties.

Several experimental studies showed their potential effects individually against oxidative stress induced by metabolic disorders including diabetes, inflammation, hepatotoxicity and cardiovascular diseases [31].

Figures 2-9 showed the effects of diabetes on Catalase and Superoxide dismutase in the various gastrointestinal tissues of stomach, duodenum, pancrease and liver respectively in alloxan-induced diabetic mellitus. In this study, there was a significant marked increase in these enzyme activities in all the tissues when compared to normal tissues. This is in agreement with several clinical and experimental studies [34].

From these results, the enzymes were observed to respond in compensatory mechanism, increasing enzyme activity in the diabetic rats, in an attempt to maintain homeostasis. SOD activity was increased in the diabetic control rats compared to that of the non-diabetic control rats. The higher SOD activity is believed to be due to increased dismutation of superoxide anions due to their increased production [34]. The activity for the diabetic rats treated with combination of silymarin and vitamin $\mathrm{C}$ was shown to be closer to that of the non-diabetic rats. This could mean that there was an initial increase in SOD activity 


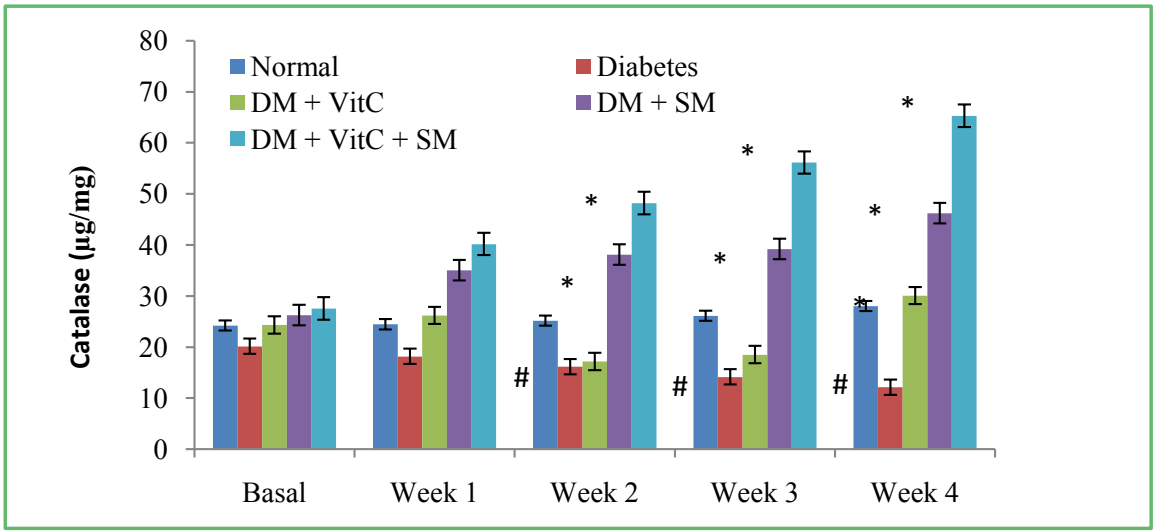

Figure 2. Effects of Alloxan-Induced DM on Gastric Catalase Levels. From Figure 2 above, Catalase activity in the Stomach showed an increasing enzyme activity in diabetic tissues when compared with treated tissues using Vitamin C, Silymarin and a combination of both. In these tissues it was also clear that diabetes significantly reduced catalase activities when compared with non-diabetic rats. ${ }^{\star}=$ Significantly increased when compared with diabetic group. \# = Significantly reduced when compared with normal group.

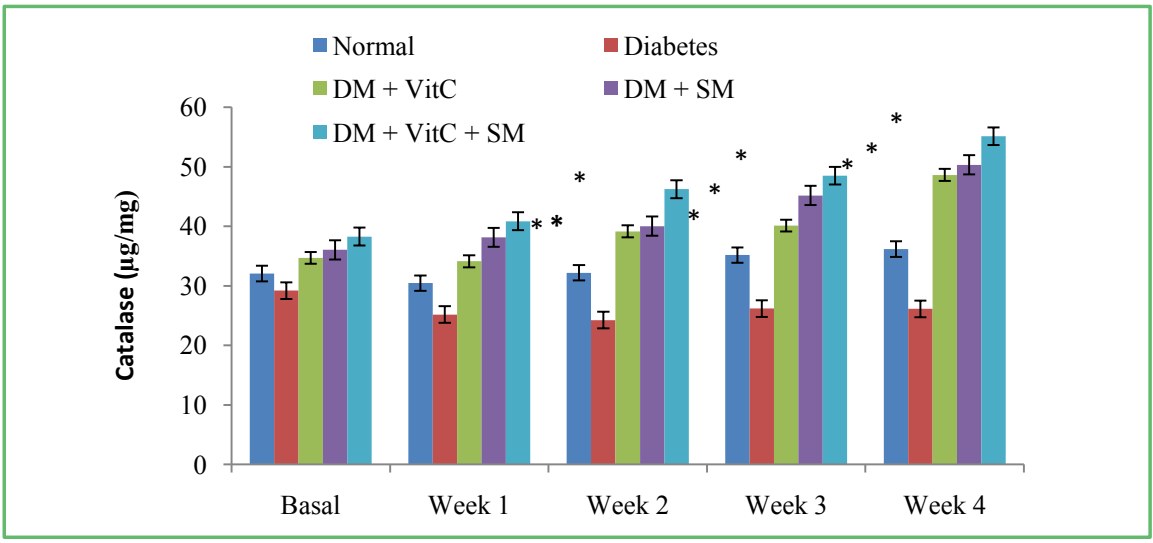

Figure 3. Effects of Alloxan-Induced DM on Duodenal Catalase Levels. *Significantly increased at $\mathrm{p} \leq 0.05$ when compared with diabetic group. \#Significantly reduced at $\mathrm{p} \leq 0.05$ when compared with normal group.

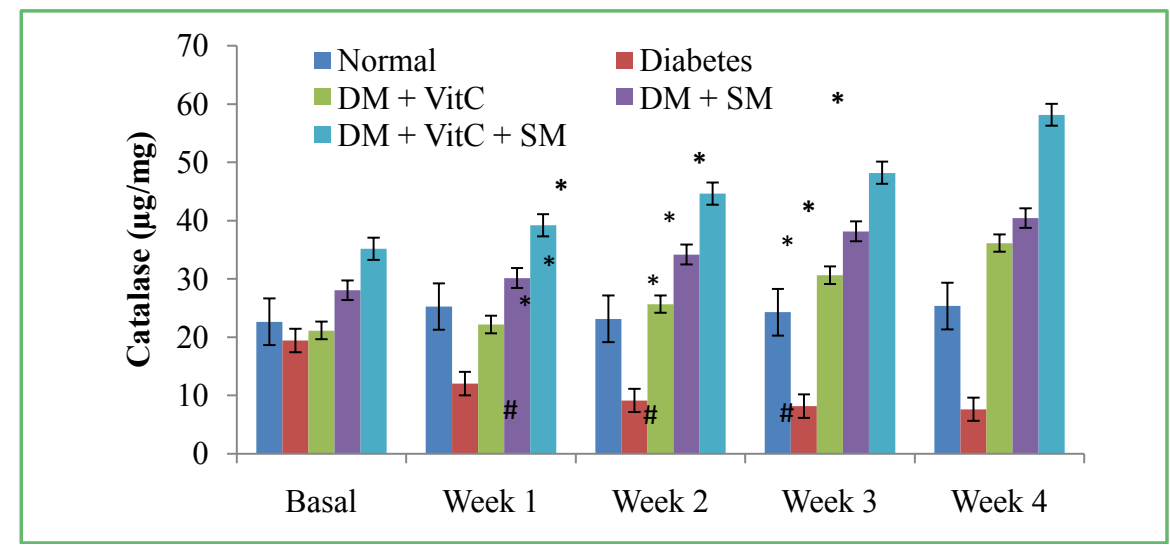

Figure 4. Effects of Alloxan-Induced DM on Pancreatic Catalase Levels. ${ }^{*}$ Significant increase when compared with diabetic group. \#Significantly decreased when compared with normal rat group. 


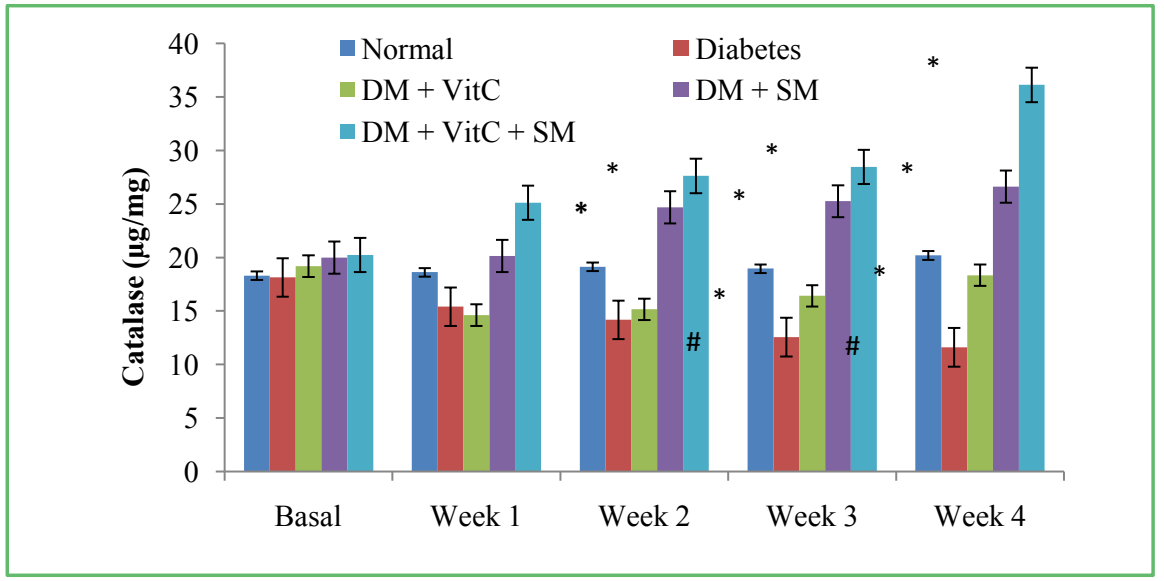

Figure 5. Effects of Alloxan-Induced DM on Liver Catalase Levels. ${ }^{\star}$ Significant increase when compared with diabetic group. \#Significantly decreased when compared with normal rat group.

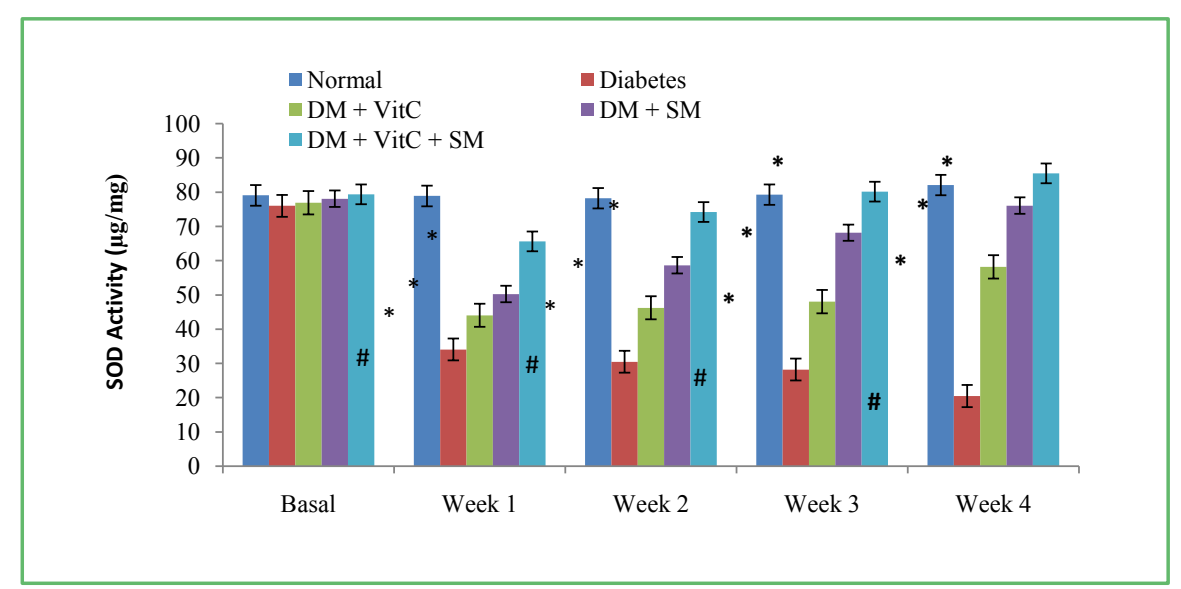

Figure 6. Effects of Alloxan-Induced DM on GastricSOD Levels. ${ }^{\star}$ Significant increase when compared with diabetic group. \#Significantly decreased when compared with normal rat group.

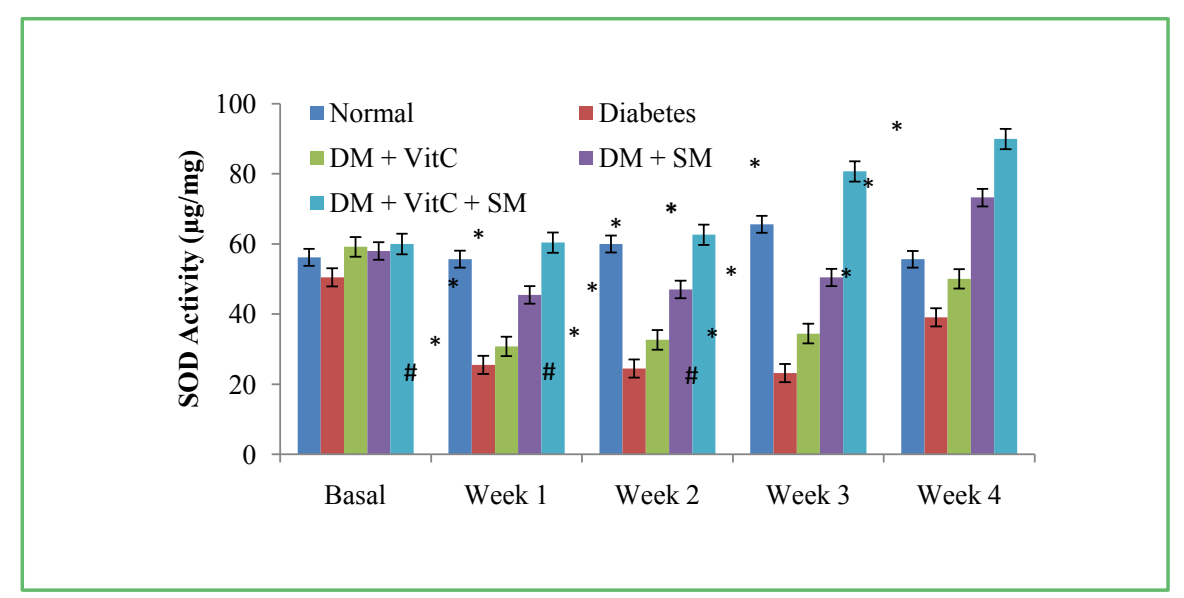

Figure 7. Effects of Alloxan-Induced DM on Duodenal SOD Levels. ${ }^{\star}$ Significant increase when compared with diabetic group. \#Significantly decreased when compared with normal rat group. 


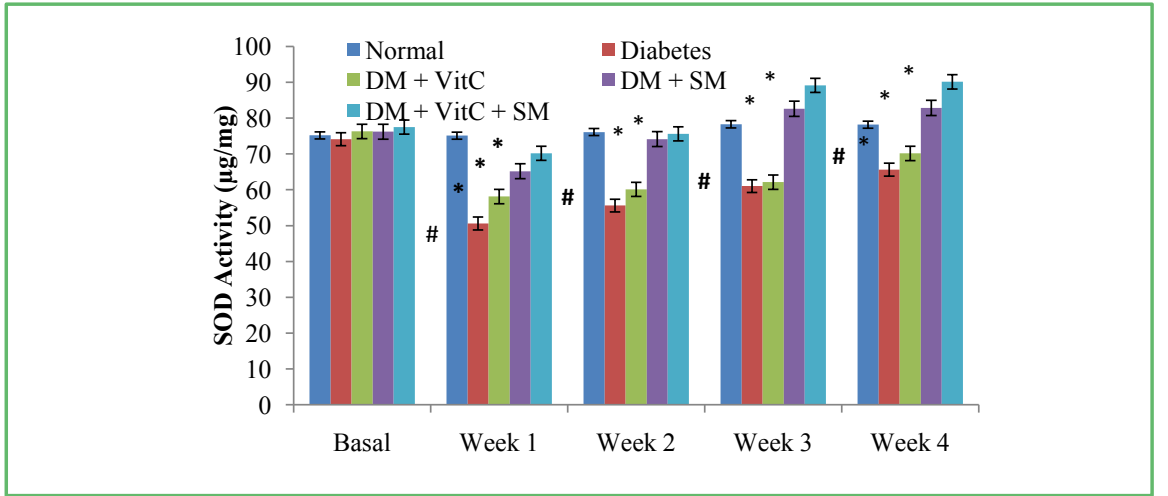

Figure 8. Effects of Alloxan-Induced DM on Pancreatic SOD Levels. ${ }^{*}$ Significant increase when compared with diabetic group. \#Significantly decreased when compared with normal rat group.

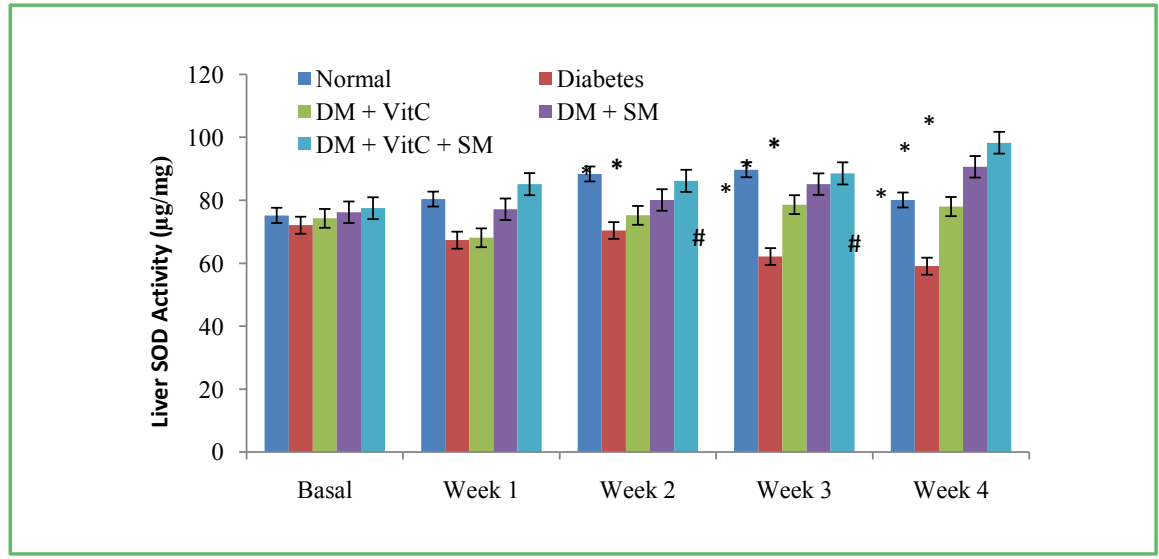

Figure 9. Effects of Alloxan-Induced DM on Liver SOD Levels. ${ }^{\star}$ Significant increase when compared with diabetic group. \#Significantly decreased when compared with normal rat group.

due to production of superoxide anions at the onset of diabetes but the administration of antioxidant vitamins would reduce further production of ROS with resulting decrease SOD activity. However, some previous investigators have shown conflicting reports on Superoxide dismutase (SOD) and Catalase (CAT) activities in diabetes, with reports indicating increased concentrations, decreased concentration, or no change at all, depending on the enzyme activity investigated. In our study, activities of antioxidant enzymes in the untreated diabetic rats were significantly reduced. These findings are in accordance with previous reports of Saravanan [35] in which low levels of SOD and CAT activity of diabetic rats were significantly increased in the antioxidant supplemented group compared with controls. Hyperglycemia results in the generation of free radicals which can exhaust antioxidant defenses thus leading to the disruption of cellular functions, oxidative damage to membranes and enhanced susceptibility to lipid peroxides [35]. Depression of the activities of antioxidant enzymes suggests increased ROS generation in the untreated diabetic rats, and therefore increased oxidative stress. The low levels of SOD and CAT activity of diabetic stress were 
significantly increased in the antioxidant supplemented group compared with controls. The increased activities of serum SOD and CAT due to vit-C and silymarin supplementation (treatment), apparently, resulted in the amelioration of the toxic effects of the ROS, generated in excess during diabetes. Based on the above, previous work had therefore suggested that antioxidant therapy may be an important adjunct treatment regimen for diabetes. Findings from present study experimentally demonstrated that the antioxidants, vitamin $\mathrm{C}$ and silymarin are beneficial in mitigating the oxidative stress-induced adverse effects, associated with diabetes mellitus.

Malondialdehyde (MDA), a lipid peroxidation product, is known to be an important predictor of oxidative stress. As part of the metabolic process free radicals and reactive oxygen species (ROS) are produce by cells [26]. Changes in lipid peroxidation are thought to be indicative of stress, aging, or damage resulting from toxic effects in cells. Free radicals caused by reactivation of fatty acids resulting from tissue damage cause increases in MDA levels. Following this, the antioxidant defense mechanism becomes active [22]. The results of our study also showed that hyperglycaemia was accompanied with increased lipid peroxidation, as evidenced by the significant increase in Malondialdehyde (MDA) concentration in the serum, stomach small intestines liver and pancreas of untreated diabetic rats. The increase in serum MDA concentration in the untreated diabetic rats may be associated with the destruction of erythrocytic membranes and various tissues, caused by the oxidative stress (Figure 10 and Figure 11). This result is in agreement with the finding that diabetes induces a significant increase in lipid peroxidation [24] [25] [26]. The significant higher level of MDA in the untreated diabetic rats, observed in the present study is also consistent with the findings of Saravana et al. [35] who noted a significant high level of MDA in the untreated diabetic rats in oxidative stress. However we noted that MDA levels remained relatively stable in the early period of stress but became significantly increased in chronic stress.

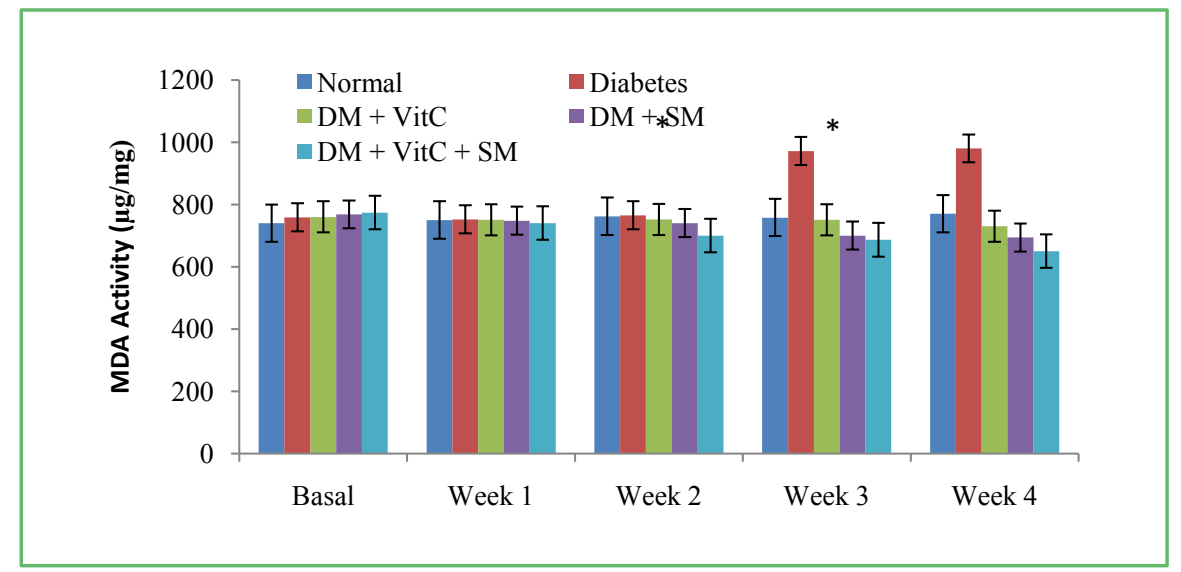

Figure 10. Effects of Alloxan-Induced DM on GastricMDA Levels. ${ }^{\star}$ Significant increase when compared with diabetic group. \#Significantly decreased when compared with normal rat group. 


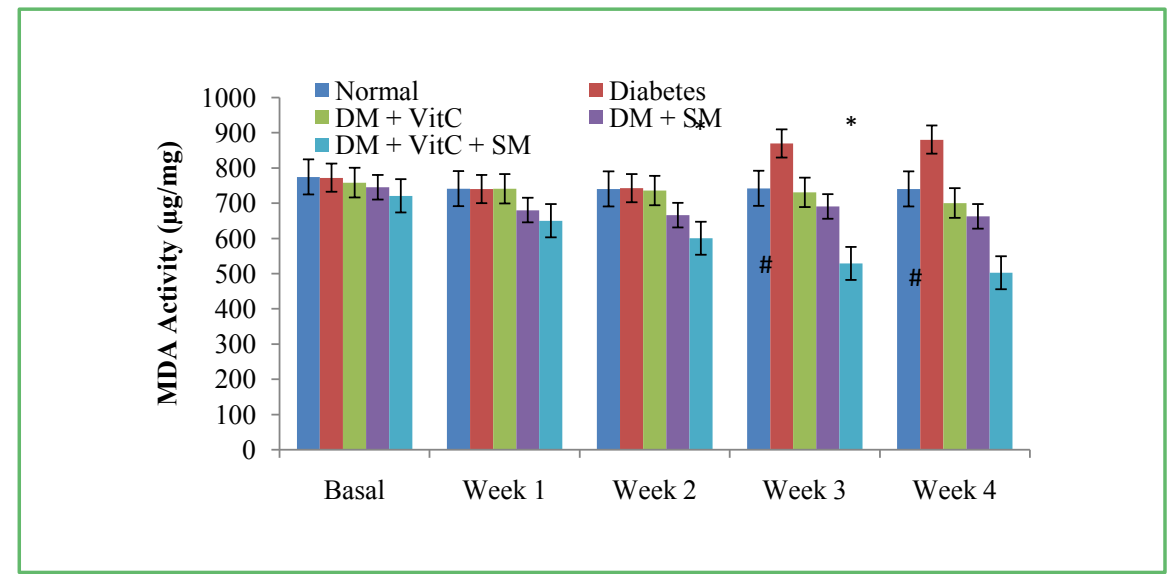

Figure 11. Effects of Alloxan-Induced DM on Liver MDA Levels. ${ }^{\star}$ Significant increase when compared with diabetic group. \#Significantly decreased when compared with normal rat group.

The lower levels of serum MDA in rats treated with silymarin and vitamin-C compared to untreated rats is suggestive that both antioxidants ameliorates the detrimental effect of oxidative stress in diabetic rats and are in accordance with the findings of Okon et al. [27]. The MDA concentration indicates the extent of lipid peroxidation and is used as a biomarker in chronic oxidative stress in cells and tissues [25].

The results of the present study also suggest that lipid peroxidation was greater in the untreated diabetic rats, and, also went further to show that silymarin and vit- $\mathrm{C}$ administration, especially their combination, in diabetic rats decreased the levels of serum and tissue lipid peroxidation considerably, subsequently restoring the activities of antioxidant enzymes. Lipid peroxides and hydroperoxides are the secondary products of oxidative stress and are unleashed as a result of the toxic effect of ROS produced during LPO in diabetes [36].

Figures 2-11 showed the effects of DM on MDA, CAT and SOD levels across selected (pancrease, stomach, duodenum and liver) gastrointestinal tissues of DM-induced, silymarin + vitamin C. treated rats.

Here, Malondialdehyde (MDA) levels were found to significantly increase from the third week of diabetes. This showed that unlike CAT and SOD, MDA levels remains stable during the early periods of stress, but as stress becomes chronic, these levels increases [30].

The immediate response of the body to the presence of these radicals is the antioxidant defense enzymes systems which arise to render them ineffective. They therefore play an important role in scavenging the toxic effects from these free radicals. These include catalase, superoxide dismutase, glutathione peroxidase and nonenzymatic antioxidants. Also, Malondialdehyde (MDA), a lipid peroxidation product, is known to be an important predictor of oxidative stress.

The improvement in body weight, (weight gain) in diabetic rats supplemented with silymarin and vitamin $\mathrm{C}$ and their combination highlights the improvement in blood glucose homeostasis which in turn promotes the body weight gain 
showing their synergistic anti-inflammatory and anti-oxidative properties. From the study this was noticed from the third week and may be attributed to the mitigation of catabolic processes by vitamin $\mathrm{C}$ and silymarin. It was also noted that the control group, animals apparently were in a generally good condition, with normal appetite, and progressive weight gain.

\section{Conclusion}

In the bid to maintain homeostasis, observations from this study show antioxidant enzymes to respond in compensatory mechanism with increasing enzyme activity indiabetic rats.SOD activity increased in the diabetic control rats compared to that of the non-diabetic control rats. The higher SOD activity is believed to be due to increased dismutation of superoxide anions due to their increased production. However, the diabetic rats treated with silymarin and vitamin $\mathrm{C}$ showed reduced activity. The activity for the diabetic rats treated with combination of silymarin and vitamin $\mathrm{C}$ was shown to be closer to that of the non-diabetic rats. This could mean that there was an initial increase in SOD activity due to production of superoxide anions at the onset of diabetes but the administration of antioxidant vitamins would reduce further production of ROS with resulting decrease in SOD activity. The current findings suggest that the increase in oxidative stress in diabetic rats was effectively reduced and controlled via the administration of antioxidant vitamins.

\section{Conflicts of Interest}

The authors declare no conflicts of interest regarding the publication of this paper.

\section{References}

[1] Abell, T.L., Camilleri, M. and Donohoe, K. (2008) American Neurogastroenterology and Motility Society and the Society of Nuclear Medicine Consensus Recommendations for Gastric Emptying Scintigraphy: A Joint Report of the American Neurogastroenterology and Motility Society and the Society of Nuclear Medicine. American Journal of Gastroenterology, 103, 753-763.

[2] Abu-El-Fattah, A.A., El-Sawalhi, M.M., Rashed, E.R. and El-Ghazaly, M.A. (2010) Possible Role of Vitamin E, Coenzyme Q10 and Rutin in Protection against Cerebral Ischemia/Reperfusion Injury in Irradiated Rats. International Journal of Radiation Biology, 86, 1070-1078. https://doi.org/10.3109/09553002.2010.501844

[3] Aleisa, A.M., Abouhashish, H.M., Ahmed, M.M., Al-Rejaie, S., Alkhamees, O.A. and Alroujayee, A.S. (2013) Ameliorative Effects of Rutin and Ascorbic Acid Combination on Hypercholesterolemia-Induced Hepatotoxicity in Female Rats. African Journal Pharmacology Pharmacology, 7, 280-288. https://doi.org/10.5897/AJPP12.745

[4] Alsaif, M.A. (2009) Beneficial Effects of Rutin and Vitamin C Coadministration in a Streptozotocin-Induced Diabetes Rat Model of Kidney Nephrotoxicity. Pakistan Journal of Nutrition, 8, 745-754. https://doi.org/10.3923/pjn.2009.745.754

[5] Alsaif, M.A. (2009) Combined Treatment of Rutin and Vitamin C improves the Antioxidant Status in Streptoxotocin-Induced Diabetic Rats. Journal of Medical Science, 
9, 1-9. https://doi.org/10.3923/jms.2009.1.9

[6] Aluwong, T., Mohammed, K., Raji, M., Dzenda, T., Govwang, F., Sinkalu, V. and Ayo, J. (2013) Effect of Yeast Probiotic on Growth, Antioxidant Enzyme Activities and Malondialdehyde Concentration of Broiler Chickens. Antioxidants, 2, 326-339. https://doi.org/10.3390/antiox2040326

[7] Budin, S.B., Othman, F., Louis, S.R., Bakar, M.A., Das, S. and Mohamed, J. (2009) The Effects of Palm Oil Tocotrienol-Rich Fraction Supplementation on Biochemical Parameters, Oxidative Stress and the Vascular Wall of Streptozotocin-Induced Diabetic Rats. Clinics, 64, 235-244. https://doi.org/10.1590/S1807-59322009000300015

[8] Bytzer, P., Talley, N.J., Hammer, J., Young, L.J., Jones, M.P. and Horowitz, M. (2002) GI Symptoms in Diabetes Mellitus Are Associated with Both Poor Glycemic Control and Diabetic Complications. The American Journal of Gastroenterology, 97, 604-611.

[9] Bytzer, P., Talley, N.J., Leemon, M., Young, L.J., Jones, M.P. and Horowitz, M. (2001) Prevalence of Gastrointestinal Symptoms Associated with Diabetes Mellitus: A Population-Based Survey of 15,000 Adults. Archives of Internal Medicine, 161, 1989-1996. https://doi.org/10.1001/archinte.161.16.1989

[10] Cade, W.T. (2008) Diabetes-Related Microvascular and Macrovascular Diseases in the Physical Therapy Setting. Physical Therapy, 88, 1322-1335.

https://doi.org/10.2522/ptj.20080008

[11] Calabrese, V.C., Cornelius, V.L., et al. (2012) Oxidative Stress, Glutathione Status, Sirtuin and Cellular Stress Response in Type 2 Diabetes. Biochimica et Biophysica Acta, 1822, 729-736. https://doi.org/10.1016/j.bbadis.2011.12.003

[12] Camilleri, M., Bharucha, A.E. and Farrugia, G. (2011) Epidemiology, Mechanisms, and Management of Diabetic Gastroparesis. Clinical Gastroenterology and Hepatology, 9, 5-12. https://doi.org/10.1016/j.cgh.2010.09.022

[13] Camilleri, M. (2007) Clinical Practice. Diabetic Gastroparesis. The New England Journal of Medicine, 356, 820-829. https://doi.org/10.1056/NEJMcp062614

[14] Forrest, A., Huizinga, J.D., Wang, X.-Y., Liu, L.-W. and Parsons, M. (2008) Increase in Stretch-Induced Rhythmic Motor Activity in the Diabetic Rat Colon Is Associated with Loss of ICC of the Submuscular Plexus. American Journal of Physiology, Gastrointestinal and Liver Physiology, 294, G315-G326. https://doi.org/10.1152/ajpgi.00196.2007

[15] Forster, J., Damjanov, I., Lin, Z., Sarosiek, I., Wetzel, P. and McCallum, R.W. (2005) Absence of the Interstitial Cells of Cajal in Patients with Gastroparesis and Correlation with Clinical Findings. Journal of Gastrointestinal Surgery, 9, 102-108. https://doi.org/10.1016/j.gassur.2004.10.001

[16] Phillips, M., Cataneo, R.N., Cheema, T. and Greenberg, J. (2004) Increased Breath Biomarkers of Oxidative Stress in Diabetes Mellitus. Clinica Chimica Acta, 344, 189-194. https://doi.org/10.1016/j.cccn.2004.02.025

[17] Pieper, A.A., Verma, A., Zhang, J. and Snyder, S.H. (1999) Poly (ADP-ribose) Polymerase, Nitric Oxide and Cell Death. Trends in Pharmacological Science, 20, 171-181. https://doi.org/10.1016/S0165-6147(99)01292-4

[18] Franke, S.I., Pra, D., da Silva, J., Erdtmann, B. and Henriques, J.A.P. (2005) Possible Repair Action of Vitamin C on DNA Damage Induced by Methyl Methanesulfonate, Cyclophosphamide, $\mathrm{FeSO}_{4}$ and $\mathrm{CuSO}_{4}$ in Mouse Blood Cells in Vivo. Mutation Research/ Genetic Toxicology and Environmental Mutagenesis, 583, 75-84. https://doi.org/10.1016/j.mrgentox.2005.03.001

[19] Kangralkar, V.A., Patil, S.D. and Bandivadekar, R.M. (2010) Oxidative Stress and 
Diabetes: A Review. International Journal of Pharmaceutical Applications, 1, 38-45.

[20] Karapehlivan, M., Atakisi, E., Atakisi, O., Yucart, R. and Pancarci, S.M. (2007) Blood Biochemical Parameters during the Lactation and Dry Period in Tuj Ewes. Small Ruminant Research, 73, 267-271. https://doi.org/10.1016/j.smallrumres.2006.12.006

[21] Karayiannakis, A.J., Bolanaki, H., Kouklakis, G., Dimakis, K., Memet, I. and Simopoulos, C. (2011) Ischemic Colitis of the Left Colon in a Diabetic Patient. Case Reports in Gastroenterology, 5, 239-245. https://doi.org/10.1159/000327981

[22] Karthikesan, K., Pari, L. and Menon, V.P. (2012) Protective Effect of Tetrahydrocurcumin and Chlorogenic Acid against Streptozotocin-Nicotinamide Generated Oxidative Stress Induced Diabetes. Journal of Functional Foods, 2, 134-142. https://doi.org/10.1016/j.jff.2010.04.001

[23] Kashyap, P. and Farrugia, G. (2010) Diabetic Gastroparesis: What We Have Learned and Had to Unlearn in the Past 5 Years. Gut, 59, 1716-1726. https://doi.org/10.1136/gut.2009.199703

[24] Nyenwe, E.A., Odia, O.J., Ihekwaba, A.E., Ojule, A. and Babatunde, S. (2003) Type 2 Diabetes in Adult Nigerians: A Study of Its Prevalence and Risk Factors in Port Harcourt, Nigeria. Diabetes Research and Clinical Practice, 62, 177-185. https://doi.org/10.1016/j.diabres.2003.07.002

[25] Obembe, A.O., Okwari, O.O., Owu, D.U., Antai, A.B. and Osim, E.E. (2008) Intestinal Motility and Transit Following Chronic Ingestion of Different Forms of Palm Oil Diets. Nigerian Journal of Physiological Sciences, 23, 95-99. https://doi.org/10.4314/njps.v23i1-2.54940

[26] Ogbonnaya, K.I. and Arem, R. (1990) Diabetic Diarrhea. Pathophysiology, Diagnosis, and Management. Archives of Internal Medicine, 150, 262-267. https://doi.org/10.1001/archinte.1990.00390140018005

[27] Okon, U.A., Owo, D.U., Udokang, N.E., Udobang, J.A. and Ekpenyong, C.E. (2012) Oral Administration of Aqueous Leaf Extract of Ocimum Gratissimum Ameliorates Polyphagia, Polydipsia and Weight Loss in Streptozotocin-Induced Diabetic Rats. American Journal of Medicine and Medical Sciences, 2, 45-49. https://doi.org/10.5923/j.ajmms.20120203.04

[28] Sanders, K.M., Ördög, T., Koh, S.D. and Ward, S.M. (2000) A Novel Pacemaker Mechanism Drives Gastrointestinal Rhythmicity. News in Physiological Sciences, 15, 291-298. https://doi.org/10.1152/physiologyonline.2000.15.6.291

[29] Vittal, H., Farrugia, G., Gomez, G. and Pasricha, P.J. (2007) Mechanisms of Disease: The Pathological Basis of Gastroparesis-A Review of Experimental and Clinical Studies. Nature Clinical Practice. Nature Gastroenterology \& Hepatology, 4, 336-346. https://doi.org/10.1038/ncpgasthep0838

[30] Wagner, H. (1981) Plant Constituents with Antihepatotoxic Activity. In: Beal, J.L. and Reinhard, E., Eds., Natural Products as Medicinal Agents, Hippokrates-Verlag, Stuttgart, Germany.

[31] Wallace, J.I. (2004) Management of Diabetes in Elderly. Clinical Diabetes, 17, 1.

[32] Ward, S.M., Beckett, E.A., Wang, X., Baker, F., Khoyi M. and Sanders, K.M. (2000) Interstitial Cells of Cajal Mediate Cholinergic Neurotransmission from Enteric Motor Neurons. Journal of Neuroscience, 20, 1393-1403. https://doi.org/10.1523/JNEUROSCI.20-04-01393.2000

[33] Ward, S.M., McLaren, G.J. and Sanders, K.M. (2006) Interstitial Cells of Cajal in the Deep Muscular Plexus Mediate Enteric Motor Neurotransmission in the Mouse Small Intestine. The Journal of Physiology, 573, 147-159. 
https://doi.org/10.1113/jphysiol.2006.105189

[34] Sankaranarayanan, C. and Pari, L. (2011) Thymoquinone Ameliorates Chemical Induced Oxidative Stress and $\beta$-Cell Damage in Experimental Hyperglycemic Rats. Chemico-Biological Interactions, 190, 148-154.

https://doi.org/10.1016/j.cbi.2011.02.029

[35] Saravanan, G. and Ponmurugan, P. (2011) Ameliorative Potential of S-Allyl Cysteine on Oxidative Stress in STZ Induced Diabetic Rats. Chemico-Biological Interactions, 189, 100-106. https://doi.org/10.1016/j.cbi.2010.10.001

[36] Sarna, S.K. (2010) Introduction. Colonic Motility: From Bench Side to Bedside. Morgan \& Claypool Life Sciences, San Rafael, CA.

https://doi.org/10.4199/C00020ED1V01Y201011ISP011 